\title{
Histological studies on the origin of planulae of the coral Pocillopora damicornis
}

\author{
W. Diah Permata ${ }^{1, *}$, R. A. Kinzie III $^{2}$, M. Hidaka ${ }^{1, * *}$ \\ ${ }^{1}$ Department of Biology, University of the Ryukyus, Nishihara, Okinawa 903-0213, Japan \\ ${ }^{2}$ Department of Zoology, and Hawai'i Institute of Marine Biology, University of Hawai'i, Hawai'i 96822, USA
}

\begin{abstract}
The coral Pocillopora damicornis develops gonads and releases planulae on a lunar cycle throughout most of its range. Planulae of $P$. damicornis in some populations display the same allozyme pattern as their mother colonies, suggesting that planulae might be produced asexually. To investigate the origin of planulae in this coral, histological studies on maturation of oocytes and early development of planulae were performed on P. damicornis in Okinawa, Japan. Small branches 3 to $5 \mathrm{~cm}$ long were sampled for histological observation from 7 colonies every day from August 24 to 30 and September 26 to 30,1997 . Blastula- and gastrula-like stages were observed for the first time in $P$. damicornis. Blastula-like embryos consisted of a poorly defined cellular cover over an indistinct yolky mass, and were approximately the same size as mature oocytes, ca $100 \mu \mathrm{m}$ in diameter. Oocytes occurred in 2 size classes, small $(<50 \mu \mathrm{m})$ and large $(>50 \mu \mathrm{m})$. A continuous series of planula developmental stages from blastulae to planulae was documented. The appearance of early embryos and small planulae occurred about the time that large oocytes disappeared. These observations, together with a lack of any sign of production of planulae by budding, strongly suggest that planulae of $P$. damicornis in this population are derived from oocytes that undergo typical embryogenesis.
\end{abstract}

KEY WORDS: Coral · Pocillopora damicornis · Reproduction · Planula brooding

\section{INTRODUCTION}

The coral Pocillopora damicornis has long been characterized as a typical planulating scleractinian (Atoda 1947. Harrigan 1972). The coral is an hermaphrodite, developing gametes and releasing planulae with a lunar periodicity (Ushioda 1983, Muir 1984, Stoddart \& Black 1985, Martin-Chavez 1986), though the time of planula release varies among locations (Atoda 1947, Stimson 1978, Harriott 1983, Ushioda 1983, Muir 1984, Richmond \& Jokiel 1984, Stoddart \& Black 1985, Ward 1992, Tanner 1996). In spite of this extensive study, the origin of the brooded planulae of $P$. damicornis is not fully understood. Hypotheses include asexual budding, origin from lipid bodies, parthenogenetic development from oocytes, and sexually produced zygotes.

\footnotetext{
*Present address: Faculty of Fisheries and Marine Science, Diponegoro University, Kampus Tembalang, Semarang 50241, Indonesia

"*Corresponding author. E-mail: hidaka@sci.u-ryukyu.ac.jp
}

\section{Histological evidence}

Several researchers have sought intermediate stages between mature oocytes and early planulae. However, they found no early cleavage, blastula, or gastrula stages, lending support to the hypothesis of an origin by budding of Pocillopora damicornis planulae (Muir 1984, Stoddart \& Black 1985, Martin-Chavez 1986, Ward 1992). Consistent with the budding hypothesis, Stoddart \& Black (1985) found no developmental stages connecting the largest ova (116 $\mu \mathrm{m}$ diameter) with the smallest planulae (160 $\mu \mathrm{m}$ length), despite observations of hundreds of contemporaneous eggs and developing planulae in 29 colonies over 2 or 3 cycles of planulation. Other histological observations suggest that gametes may be involved in parthenogenetic planula production. Martin-Chavez (1986) observed a clear temporal relationship between oocyte maturation and planula production. However, he presumed that sperm were resorbed before they became fully mature and he suggested that planulae of Pocillo- 
pora damicornis are produced by parthenogenesis from mature oocytes. Histological observations of correlation between gametogenesis and planula production indicated that sexual reproduction may occur in some populations (Ushioda 1983, Martin-Chavez 1986). However, Muir (1984) and Stoddart \& Black (1985) found that planulae appeared before gametogenesis was complete in some $P$. damicornis colonies, suggesting no role for gametes in planula production. Muir (1984) proposed that planulae of $P$. damicornis develop from lipid storage bodies which occur in the pharynx, since these pharyngeal lipid bodies had a histological structure superficially similar to the earliest planula stages.

\section{Genetic evidence}

Stoddart (1983) found that planulae of Pocillopora damicornis in Western Australia and Hawai'i consistently displayed the same allozyme pattern as the parent colonies for 5 polymorphic loci including 1 or 2 heterozygous loci. He concluded that planulae of $P$. damicornis are produced asexually and suggested that planulae may develop either by budding or by parthenogenesis. Budded planulae would be produced mitotically by growth of somatic cells, while parthenogenetically produced planulae would be produced from unfertilized oocytes. Genetical structure within populations of $P$. damicornis in southwestern Australia also suggested that $P$. damicornis there reproduce largely asexually, and that while asexual proliferation through planulae and fragments plays a primary role in population maintenance, sexually produced propagules may act to connect separate populations (Stoddart 1984a,b). Benzie et al. (1995) found high levels of genotypic diversity in populations of $P$. damicornis at One Tree Island, Great Barrier Reef (GBR), and concluded that reproduction there was predominantly sexual. Ayre et al. (1997) also found high levels of genotypic diversity in 9 populations of $P$. damicornis from 3 widely separated reefs on the GBR and concluded that those populations are maintained by the recruitment of sexually generated larvae.

It is ironic that, while reproduction has been studied in Pocillopora damicornis more than any other scleractinian species, the origin of its brooded planulae still remains enigmatic. To investigate this unanswered question, we made histological observations on branches of $P$. damicornis that were collected daily around third quarter moon in Okinawa, Japan, when planula development was thought to be initiated. Here we provide the first report on early embryonic stages in $P$. damicornis, and present morphological evidence that planulae of $P$. damicornis in this population are derived from oocytes.

\section{MATERIALS AND METHODS}

Seven colonies of Pocillopora damicornis were collected from Sesoko Beach and Bise in northern Okinawa from August to September 1997 (Table 1). Colonies were labeled and transferred to Sesoko Station, Tropical Biosphere Research Center, University of the Ryukyus. All colonies were held in individual plastic buckets supplied with running unfiltered seawater at ambient temperature. To check lunar periodicity of planulation, planulae were collected by filtering overflowing seawater through planula collectors (Hidaka 1985) around first quarter moon from August to October 1997.

To observe early embryogenesis in Pocillopora damicornis, branches were collected from each of 7 colonies every day for several days around third quarter moon, as Ushioda's (1983) data suggested that early development of planulae should occur around third quarter moon in $P$. damicornis in Okinawa if they are produced sexually. Sampling of branches from 6 colonies commenced 12 to $19 \mathrm{~d}$ after collection of the colonies, from August 24 to 30,1997 . Sampling from a seventh colony commenced $2 \mathrm{~d}$ after collection, from September 26 to 30,1997 . Branches 3 to $5 \mathrm{~cm}$ long were collected using cutting pliers, and about $1 \mathrm{~cm}$ of both tip and base of the branches were removed because intermediate segments of branches in P. damicornis were reported to be more fecund than either tips or bases (Harrigan 1972).

Table 1. Pocillopora damicornis. Planulation and presence of lipid bodies in colonies used for histological studies. nd: no data. SB and B represent colonies collected at Sesoko Beach and Bise, respectively

\begin{tabular}{|c|c|c|c|c|c|c|}
\hline \multirow[t]{2}{*}{ Colony } & \multirow{2}{*}{$\begin{array}{c}\text { Date of } \\
\text { collection } \\
(\mathrm{mo} / \mathrm{d} / \mathrm{yr})\end{array}$} & \multirow{2}{*}{$\begin{array}{l}\text { Sampling of } \\
\text { branches }\end{array}$} & \multirow{2}{*}{$\begin{array}{c}\text { Lipid } \\
\text { bodies }^{a}\end{array}$} & \multicolumn{3}{|c|}{ Planula release $^{b}$} \\
\hline & & & & $\begin{array}{c}\text { Aug } \\
10-16\end{array}$ & $\begin{array}{c}\text { Sep } \\
10-13\end{array}$ & $\begin{array}{c}\text { Oct } \\
9-12\end{array}$ \\
\hline SB9712 & $08 / 05 / 97$ & $08 / 24-30 / 97$ & + & + & - & - \\
\hline SB9715 & $08 / 05 / 97$ & $08 / 24-30 / 97$ & + & - & - & + \\
\hline B9713 & $08 / 05 / 97$ & $08 / 24-30 / 97$ & + & ++ & + & + \\
\hline B9714 & $08 / 05 / 97$ & $08 / 24-30 / 97$ & - & ++++ & ++ & + \\
\hline B9715 & $08 / 12 / 97$ & $08 / 24-30 / 97$ & + & ++ & + & + \\
\hline B9716 & $08 / 12 / 97$ & $08 / 24-30 / 97$ & + & - & + & + \\
\hline B9719 & $09 / 24 / 97$ & $09 / 26-30 / 97$ & - & nd & nd & ++ \\
\hline \multicolumn{7}{|c|}{$\begin{array}{l}{ }^{a}+\text { : lipid bodies were observed; -: lipid bodies were uncommon or not } \\
\text { observed } \\
\text { b Number of planulae released per cycle. }-: \text { no planulae released; } \\
+:<30 \text { planulae }++: 30-100 \text { planulae }+++: 100-200 \text { planulae; } \\
++++>200 \text { planulae }\end{array}$} \\
\hline
\end{tabular}


Within $30 \mathrm{~min}$ after collection, branch segments were fixed in $10 \%$ formaldehyde in seawater for $24 \mathrm{~h}$. The fixed branches were decalcified in a 1:1 mixture of $10 \%$ acetic acid and $10 \%$ formaldehyde in tap water for approximately $2 \mathrm{wk}$. Tissue was then peeled off, cut to $1 \times 1 \mathrm{~cm}$ pieces, dehydrated in a graded series of ethanol and cleared using xylene. Tissues were embedded in paraffin and $10 \mu \mathrm{m}$ sections were cut and stained with Delafield's haematoxylin and eosin.

Histological sections were observed under a light microscope (NIKON Labophot-2). At least 10 polyps were observed for each branch and 22 to 40 sections were observed for each polyp. The stages of oocytes and testes were classified according to Stoddart \& Black (1985). Early embryos were identified by referring to previous reports on early embryogenesis in the brooding corals; Acropora cuneata, A. palifera (Kojis 1986), Favia fragum (Szmant-Froelich et al. 1985), Porites astreoides (Chornesky \& Peters 1987) and $P$. porites (Tomascik \& Sander 1987).

For measurements of size of oocytes, testes, and planulae, sections that contained the maximum planar area of oocytes, testes and planulae, respectively, were selected and their photomicroscopic images were printed using a video printer (Sony UP-850) and a video camera (Victor TK-910) attached to the microscope. All measurements were made on the video prints. The diameter of oocytes was measured using an electric caliper (NSK, Max-Cal). The contour of each testis was traced onto tracing paper and digitized using a scanner (HP Scanjet IIcx). The crosssectional area of each testis was then measured on a computer using $\mathrm{NIH}$ Image. Since planulae were elliptical in many sections, the size of planulae was expressed with a size index, that is, a geometric mean of the short and long axes of the section of planulae. To estimate the growth rate of planulae, the regression of mean size index of planulae on time was calculated for each colony that contained planulae.

\section{RESULTS}

\section{Planulation}

All 7 colonies of Pocillopora damicornis released planulae at least once from August to October 1997 (Table 1). Planulae were released for 5 to $6 \mathrm{~d}$ around first quarter moon. Three colonies (B9713, B9714, and B9715) released planulae repeatedly for 3 mo and 1 colony released planulae consecutively for $2 \mathrm{mo}$.

\section{Gametogenesis}

Six out of 7 colonies developed oocytes but only 3 had both oocytes and testes. Oocytes and testes developed in mesenteries and were enveloped by mesoglea and gastrodermis. Mature oocytes and testes protruded into the gastrovascular cavity and were connected to a mesentery by a stalk.

Oocytes were classified into 4 stages based on morphology and size (see Fig. 1). Histograms of oocyte diameter (see Fig. 4) indicated that there were 2 oocyte size classes; small $(<50 \mu \mathrm{m})$ and large $(>50 \mu \mathrm{m})$. Small and large oocytes could be further classified into 2 stages each, based on morphology following Stoddart \& Black (1985).

Stage I oocytes were less than $30 \mu \mathrm{m}$ in diameter and had a germinal vesicle with a prominent nucleolus.

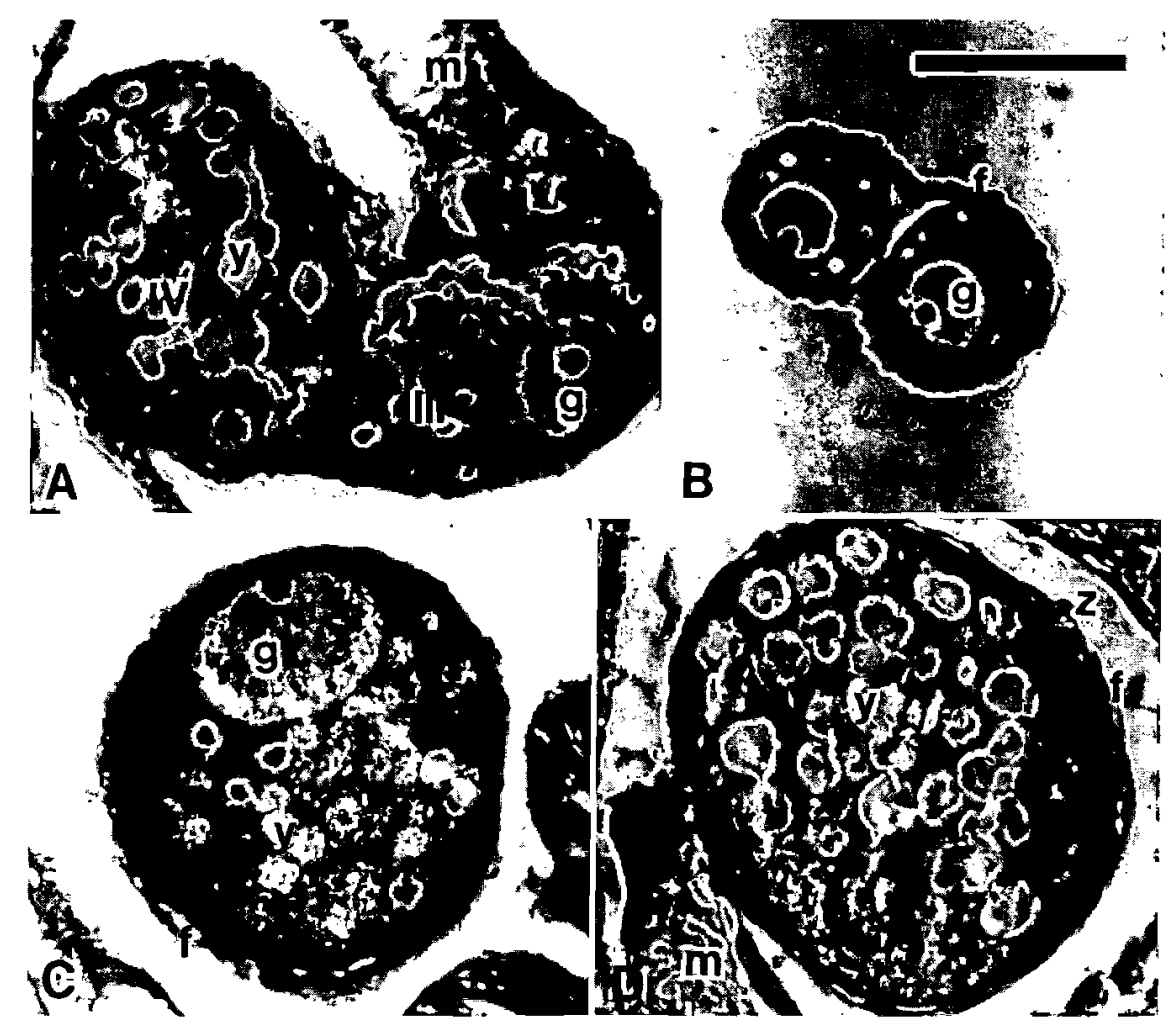

Fig. 1. Oocyte maturation in Pocillopora damicornis. (A) A mesentery containing stages I, III and IV oocytes. (B) Stage II oocytes surrounded by a follicle layer. (C) Stage III oocyte. A large germinal vesicle located at the periphery of the oocyte. (D) Stage IV oocyte. The germinal vesicle is no longer apparent at this stage and the follicle layer contains zooxanthellae. f: follicle layer; g: germinal vesicle; m: mesentery; y: yolk granules; z: zooxanthellae. Scale bar $=50 \mu \mathrm{m}$ 
Only a few yolk granules were present, located at one side of the oocyte (Fig. 1A). Stage II oocytes ranged from 30 to $50 \mu \mathrm{m}$ in diameter. Yolk granules were arrayed in a circle around the germinal vesicle (Fig. 1B). Stage III oocytes ranged from 50 to $70 \mu \mathrm{m}$ in diameter. The germinal vesicle was more prominent and located at the periphery of the cytoplasm. Yolk granules were distributed throughout the cytoplasm. A vitelline membrane or cortical layer was observed at the surface of the oocyte (Fig. 1C). Stage IV oocytes were about $100 \mu \mathrm{m}$ in diameter and had a thick vitelline membrane or cortical layer (Fig. 1D). The germinal vesicle was no longer apparent, and the oocyte was surrounded by a follicle layer. Some follicle cells contained zooxanthellae, but the oocytes at this stage were still without zooxanthellae.

Only stages II and III of the testes stages described by Stoddart \& Black (1985) were recognized in our material. Stage II testes had a thick spermatogonial wall and were attached to a mesentery by a stalk (Fig. 2A). Stage III testes were packed with spermatids and had a thinner spermatogonial wall (Fig. 2B). In some large testes, a central lumen occurred. Sperm were sometimes observed free in the coelenteron and appeared to be released from the testis (Fig. 2C), though this may be an artifact due to histological technique (Stoddart \& Black 1985).

\section{Embryogenesis}

Bastula- and gastrula-like embryos as well as planulae at various developmental stages were observed (Fig. 3). The earliest stage embryo had a poorly defined cellular layer covering an indistinct yolky mass that was almost the same size as mature oocytes, ca $100 \mu \mathrm{m}$ (Fig. 3A). A blastocoel was not evident and the early embryo appeared to be a stereoblastula. Later, when the embryos reached a gastrula-like stage, the ectodermal layer became more defined (Fig. 3B). The gastrula-like embryos were solid without an archenteron (stereogastrula) and the blastopore was filled with yolky cells. No zooxanthellae were seen in embryos at this stage. Late gastrulae were oval in shape and had distinct columnar ectodermal cells and a well-defined mesogleal layer (Fig. 3C). An oral pore and gastrovascular cavity were present. Zooxanthellae were seen in the early gastrovascular cavity (Fig. 3C), suggesting that zooxanthellae may be taken up by the planula through the oral pore and into the endodermal cells.
Larvae which had a well-developed gastrovascular cavity and ectoderm and endoderm similar to those of planulae at more advanced stages were termed early planulae (Fig. 3D). The size index of early planulae was greater than $130 \mu \mathrm{m}$. Zooxanthellae were seen
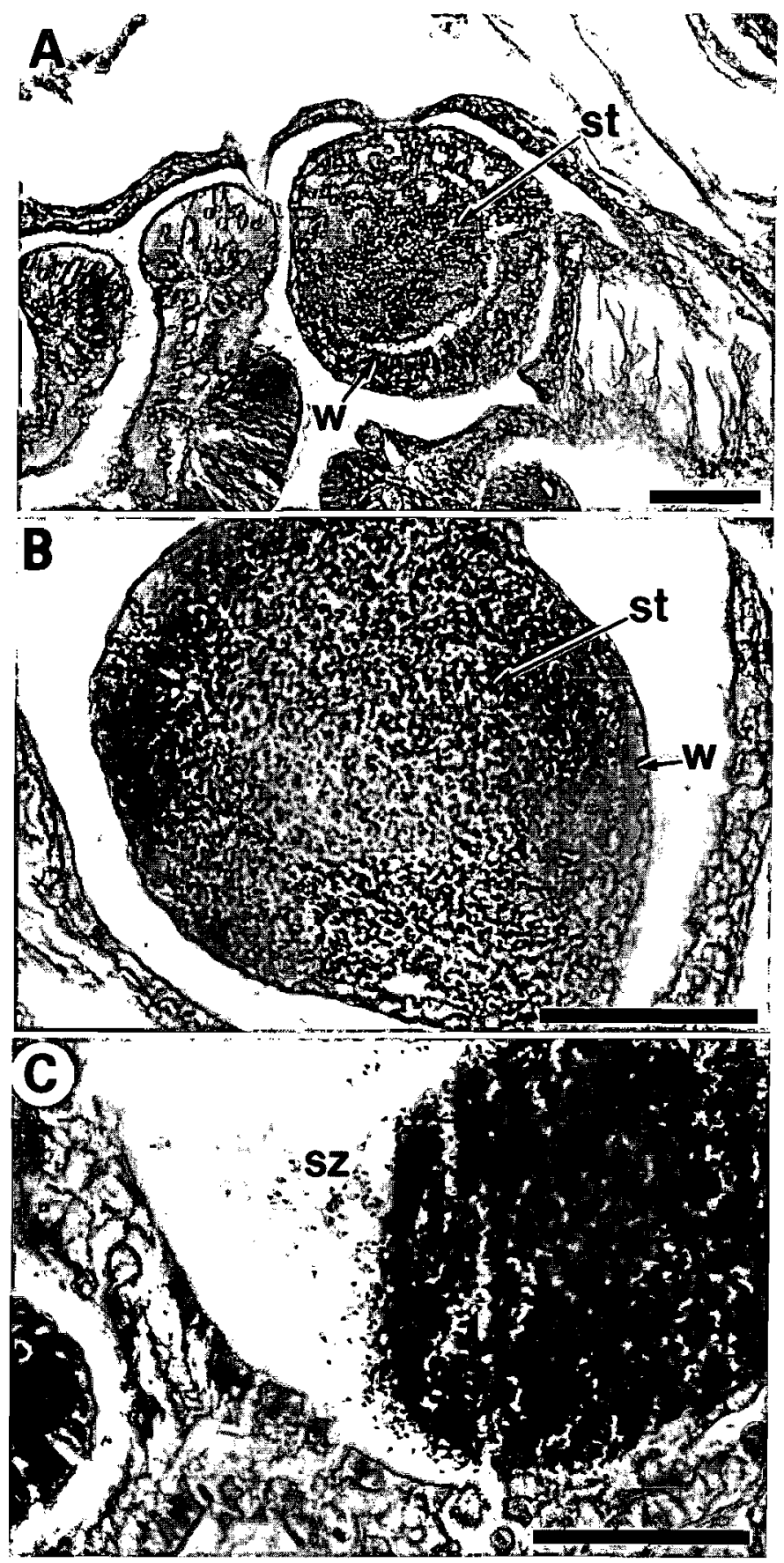

Fig. 2. Testes of Pocillopora damicornis. (A) Stage II testis surrounded by a thick spermatogonial wall. (B) Stage III testis filled with spermatids and surrounded by a thin spermatogonial wall. (C) Spermatozoa free in the coelenteron. st: spermatid; sz: spermatozoa; w: spermatogonial wall. Scale bars $=50 \mu \mathrm{m}$ 
scattered in the gastrovascular cavity of the planulae as well as in the endodermal layer (Fig. 3D). Developing planulae with up to 3 pairs of mesenteries were observed (Fig. 3E, F).

We found a total of 52 early embryos whose diameter was less than $110 \mu \mathrm{m}$. Four of them were blastula-

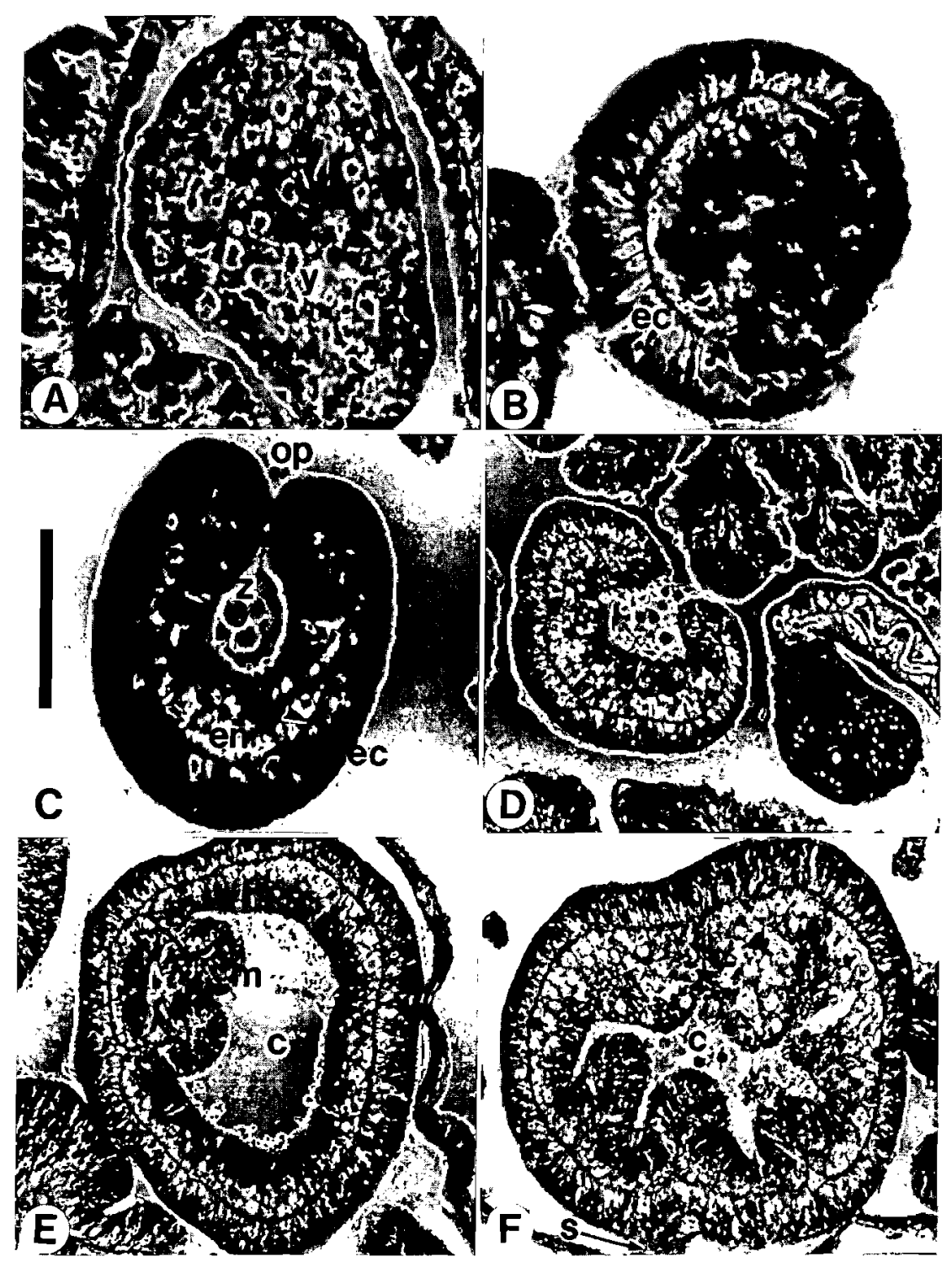

Fig. 3. Embryos and planulae of Pocillopora damicornis at various stages of development. (A) A blastula-like embryo located inside a tentacle. The inside of the embryo is filled with yolky material and no blastocoel is evident. (B) A gastrula-stage embryo. This embryo contains no zooxanthellae. [C] A late-gastrula with distinct columnar ectoderm and endoderm separated by a mesogleal layer (arrowhead). The oral pore and the gastrovascular cavity are visible. Zooxanthellae can be seen in the gastrovascular cavity. (D) An early planula and stage III oocytes. Zooxanthellae can be seen both in the gastrovascular cavity and the endoderm. (E) A planula with well-defined gastrovascular cavity and a pair of mesenteries. (F) A planula with 3 pairs of developing mesenteries. Note the presence of stalk-like structure connecting the planula to the mesentery. c: gastrovascular cavity; en: endoderm; ec: ectoderm; $m$ : mesentery; o: oocytes; op: oral pore; s: stalk; y: yolk granules; z: zooxanthellae. Scale bar $=50 \mu \mathrm{m}$ for $A, B$ and $C, 100 \mu \mathrm{m}$ for $D, E$ and F stage embryos. Two of the blastulae were found inside tentacles. Some gastrulae and early planulae were in the gastrovascular cavity of the coenosarc them were found in the gastrovascular cavity of polyps. Because the coral branches were fixed without anesthetization, it is likely that embryos and small planulae were squeezed from the gastrovascular cavity during polyp contraction upon fixation. While some planulae were connected to a mesentery by a stalk (Fig. 3F), most planulae were seen without an apparent connection.

\section{Relationship between gametes and planulae}

Planulae were observed in 5 out of the 6 colonies which had gonads. Embryos and early planulae first appeared on August 25 to 26 (lunar days 23 to 24). In September, sampling of branches commenced on the 26th (lunar day 25) and the branches already contained early planulae. Embryos and early planulae were last seen on August 29 (lunar day 27) and September 29 (lunar day 28) (Fig. 4).

The histogram of oocyte, embryo and planula sizes combined showed that the early embryos and the mature oocytes are almost the same size (Fig. 4). Some planulae were observed together with mature or small oocytes in the same polyp (Fig. 3D), while others were found in polyps with testes. However, in colonies that contained planulae, large oocytes were usually few in number or not observed at all (Figs. $4 \& 5$ ). Small oocytes were observed throughout this study, even when the polyps contained planulae (Figs. 4 \& 5).

Mean diameters of oocytes and planulae are plotted against time to show their growth rate. In 2 out of 3 colonies, the regression of mean planula size index on time was significant (regression analy- 


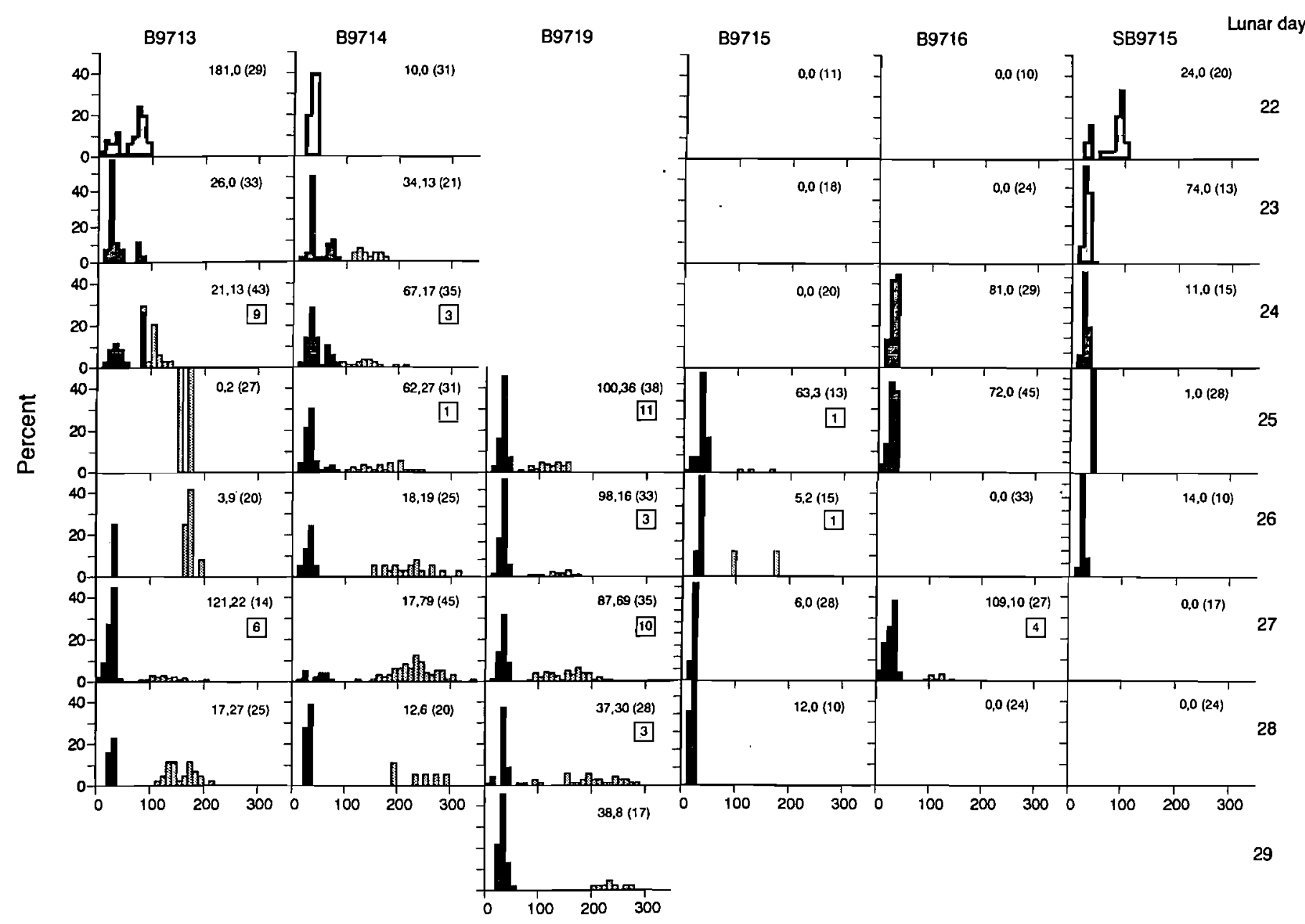

Fig. 4. The size of oocytes and embryonic planulae of Pocillopora damicornis from 6 colonies (code no. B9713-SB9715). The $\mathrm{x}$-axis represents the diameter of oocytes and size index of developing planulae (in $\mu \mathrm{m}$ ). The $y$-axis shows the percent of items in each colony in the sample. Solid and shaded bars indicate the percent of oocytes and that of embryos and planulae combined, respectively. The numbers at the upper right of each histogram represent the number of oocytes (left), and the number of embryos and planulae (right) measured, i.e. the sample sizes for each histogram. The numbers in the brackets represent the number of polyps observed. The numbers in the squares represent the number of early embryos whose diameter was less than $110 \mu \mathrm{m}$. The histograms are arranged based on lunar days, where lunar day 1 is new moon

sis, $\mathrm{p}<0.001$ ) (Fig. 5B,C). The initial linear growth rate of planulae, which was estimated from the slope of the regression line, was about $25 \% \mathrm{~d}^{-1}$. Since mature oocytes are about $100 \mu \mathrm{m}$ in diameter, the regression suggests that planula development began approximately on lunar days 22 (August 24) or 24 to 25 (September 25 to 26).

Testes were observed in branches from 3 out of 6 colonies that had gonads. Large testes were observed in branches sampled on August 24 to 25 (lunar days 22 to 23), but large testes were not seen in samples from August 26 to 27, suggesting that sperm were shed before this day (Fig. 6). The disappearance of testes on lunar days 24 to 25 roughly coincided with the appearance of early planulae on lunar days 23 to 27 .

\section{Lipid bodies and other planula-like structures}

Lipid bodies were common in 5 colonies, but rarely observed in the other 2 colonies (Table 1). Lipid bodies consisted of gastrodermis and mesoglea and displayed a meshwork structure due to lipid granules that filled endodermal cells (Fig. 7A). Zooxanthellae were sometimes found in lipid bodies. Some polyp tissues with lipid bodies superficially resembled early planulae (Fig. 7B). They were composed of ectodermal and endodermal layers, but neither layers showed the dense distribution of nuclei near the apical surface which was characteristic of planulae (Fig. 3E,F). Other structures that looked like embryos were also observed (Fig. 7C), but they were similar to what Martin- 

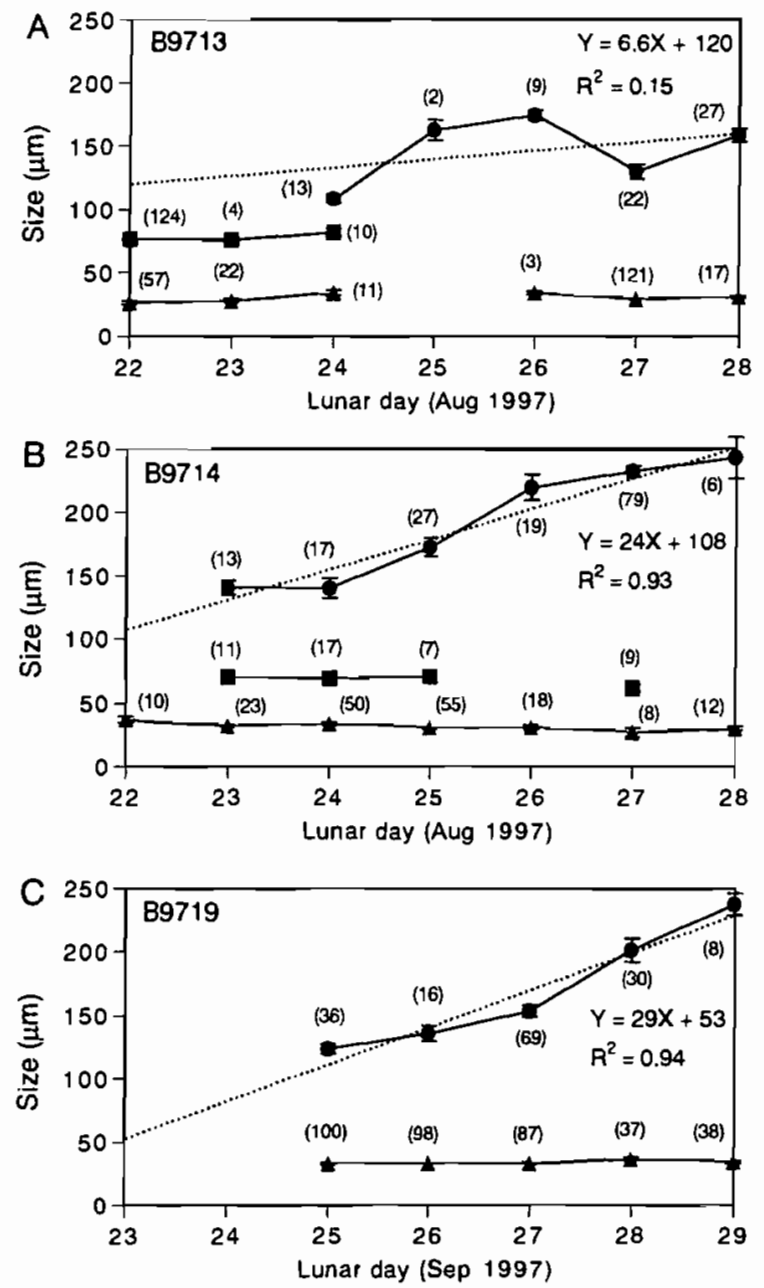

Fig. 5. Growth curve of oocytes and planulae of Pocillopora damicornis. Data are given for 3 colonies (A), (B), and (C). The mean diameter of small size class oocytes $(\boldsymbol{\Lambda})$, large size class

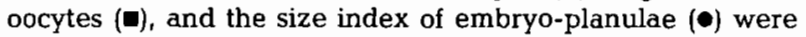
plotted against time. The numbers in brackets represent the number of oocytes or developing planulae measured. The vertical bars indicate standard errors of the means. The dotted line represents the regression line of the size of planulae on time. $\ln (\mathrm{B})$ and $(\mathrm{C})$, the size of planulae was significantly correlated with time

Chavez (1986) described as resorbed testes. No other structures that suggested production of planulae by budding were found.

\section{DISCUSSION}

In spite of the fact that the reproductive biology of Pocillopora damicornis has been intensively studied for decades, early embryos had never been observed in P. damicornis (Harriott 1983, Muir 1984, Stoddart \& Black 1985, Martin-Chavez 1986, Ward 1992, Tanner 1996). This, together with the finding that planulae of
P. damicornis in some populations are genotypically identical to their source colony, supported the hypothesis of an asexual origin of planulae in this coral (Stoddart 1983, Muir 1984). Histological studies on gamete maturation and planula appearance, however, suggested that there is some temporal relationship between gamete maturation and planula production in P. damicornis (Ushioda 1983, Martin-Chavez 1986). Genetic studies on populations of $P$. damicornis in Australia's GBR support the suggestion that sexual reproduction does occur in some populations of P. damicornis (Benzie et al. 1995, Ayre et al. 1997). Ward (1992) suggested that $P$. damicornis at Rottnest Island, Western Australia, reproduces both by asexually produced planulae and, sexually, by spawned gametes.

Our observations are the first to show blastula- and gastrula-like embryos in Pocillopora damicornis. The presence of intermediate stages between mature oocytes and early planulae, and the congruence in size of mature oocytes and the smallest planulae strongly suggest that planulae of $P$. damicornis in this popula-

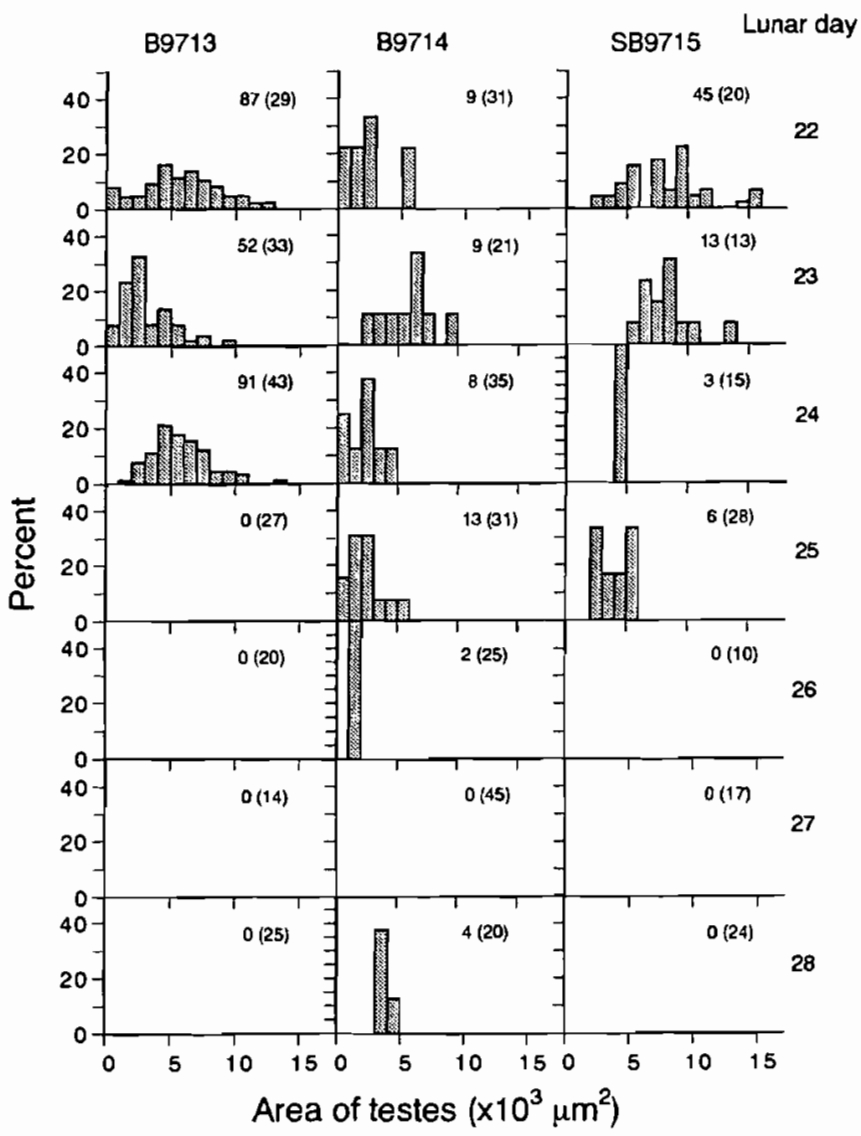

Fig. 6. Maximum area of testes in sections of polyps of Pocillopora damicornis from 3 colonies. The numbers at the upper right of each histogram represent the number of testes measured in each sample. The numbers in brackets represent the number of polyps observed 


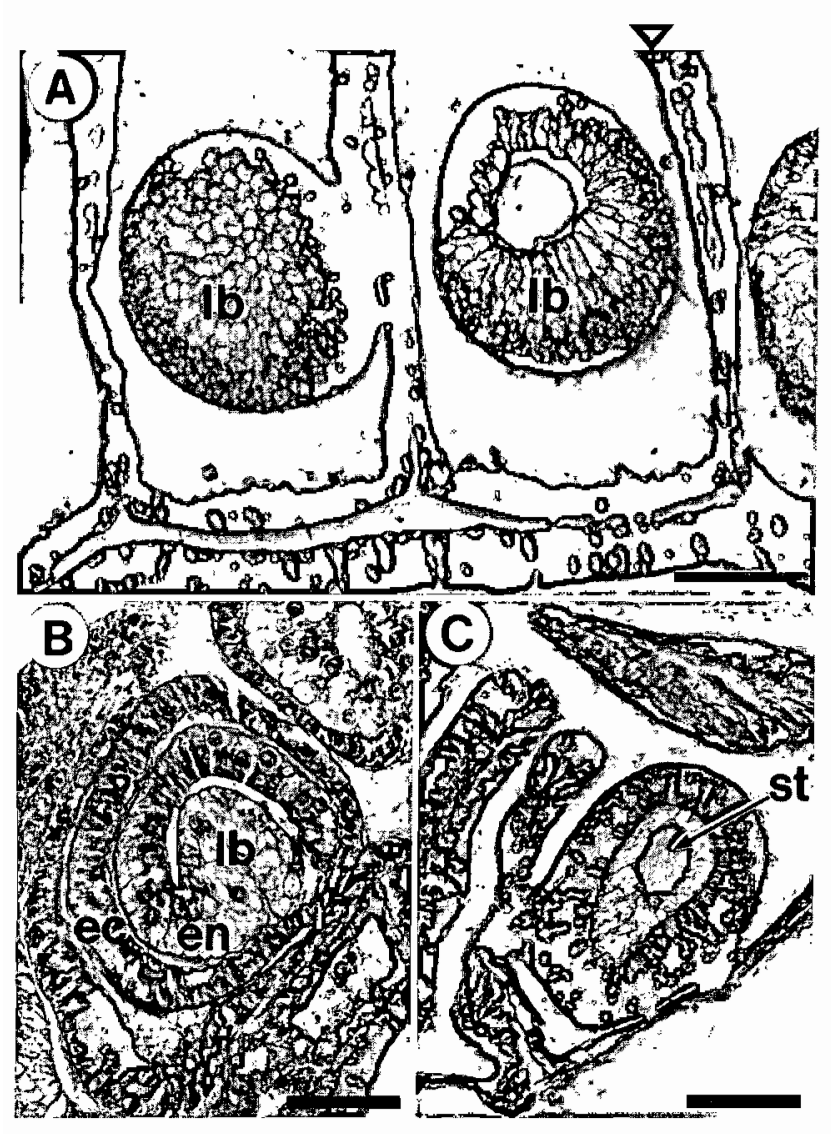

Fig. 7. Lipid bodies and other planula-like structures of PocilIopora damicornis. (A) Lipid body showing a meshwork structure. (B) Polyp tissue with a 2-layered structure which superficially resembled a planula. The inner layer had a lipid body. (C) An oval-shaped structure connected to the mesentery by a stalk. The inner region contained many dots which probably are degenerating spermatids. en: endoderm; ec: ectoderm; lb: lipid body. Scale bar $=50 \mu \mathrm{m}$

tion are produced from oocytes. The observation that the disappearance of large testes roughly coincided with the appearance of these planulae further suggests that planula production in this population may be sexual. Failure to observe early embryonic stages in earlier studies may have been due to the rapid development of fertilized ova to planulae (Harriott 1983, Stoddart \& Black 1985).

The blastula-like embryos of Pocillopora damicornis appeared as spheres of yolk granules surrounded by a single layer of epithelium. A blastocoel was not evident and the form of the blastula of $P$. damicornis may be a stereoblastula as reported for the brooding species Favia fragum (Szmant-Froelich et al. 1985) and Balanophyllia elegans (Fadlallah \& Pearse 1982). The blastula-like embryos of $P$. damicornis observed in the present study were similar to the earliest stage brooded embryos of Porites porites in that the outer layer of the embryos was not clearly delineated from the inner yolky mass (Tomascik \& Sander 1987). The presence of large amounts of yolky material in the early embryonic stages of $P$. damicornis indicates a link between mature oocytes and planulae as suggested for $P$. porites (Tomascik \& Sander 1987).

The number of large oocytes decreased shortly before planulae appeared. Large oocytes were rarely observed in colonies that contained planulae. When both large oocytes and planulae were present in a colony, the number of large oocytes was usually small (Fig. 4). These observations also suggest that planulae of Pocillopora damicornis in the Okinawan population are derived from large (ca $100 \mu \mathrm{m}$ ) oocytes. Small oocytes were observed throughout the sampling period. These small oocytes would have probably matured in subsequent reproductive cycles.

The disappearance of large testes was also temporally related to the appearance of the early planulae (Figs. 4 \& 6). However, some polyps contained both planulae and testes. Six colonies sampled in August 1997 were held in individual buckets supplied with running unfiltered seawater for 12 to $19 \mathrm{~d}$ before the sampling of branches commenced. It is not likely that cross-fertilization occurred in these colonies. Planulae observed in this study might have developed by selffertilization, though the possibility that planulae developed by parthenogenesis cannot be excluded. Synchronous spawning of sperm is probably not as crucial for fertilization in brooding corals as in broadcast spawners since brooders might be able to retain mature oocytes for some time

Embryos and early stage planulae first appeared at third quarter moon (lunar days 23 to 24). Regression of planula size on time was significant in 2 out of 3 cases. This regression line shows an initial linear growth rate of about $25 \% \mathrm{~d}^{-1}$. Based on this estimate of planula growth rate, and the size of mature oocytes, fertilization and early development probably commenced on lunar day 22 in August or lunar days 24 to 25 in September. This is a few hours to a maximum of $2 \mathrm{~d}$ before planulae were identifiable. Thus, oocytes are probably fertilized about 2 wk before planulation. Szmant-Froelich et al. (1985) observed that embryos were brooded for about 3 wk before release in Favia fragum, which has a lunar periodicity of planulation. Most embryos and early planulae of Pocillopora damicornis were found free in gastrovascular cavity as reported for Favia fragum (Szmant-Froelich et al. 1985) and Porites astreoides (Chornesky \& Peters 1987).

Blastula- and gastrula-stage embryos did not contain zooxanthellae although the follicle layer surrounding mature oocytes did contain algal symbionts (Fig. 1D). Zooxanthellae were first observed in the gastrovascular cavity of early planulae which had already developed an oral pore (Fig. 3C), suggesting that zooxan- 
thellae may enter planulae through the oral pore. Zooxanthellae were also first seen entering embryos at about this stage in Favia fragum (Szmant-Froelich et al. 1985). In F. fragum, however, zooxanthellae appeared to enter early planulae through the ectoderm near the oral pore (Szmant-Froelich et al. 1985).

There was considerable variation in gonad maturation and planula development among colonies as well as among branches. This might be due to inter-colony variation in planula production and to the fact that gamete maturation and planula development are not strictly synchronous among branches of a Pocillopora damicornis colony. As noted above, synchrony may be less important in brooding species with internal fertilization. Colonies of $P$. damicornis show considerable inter-colony variation in numbers of planulae released (e.g. Harriott 1983, Ward 1992, Tanner 1996). Harrigan (1972) reported that polyp fecundity varied widely within and among branches of $P$. damicornis.

Histological examination of Pocillopora damicornis did not reveal any indications of planulae developing from polyp tissue by budding. Contrary to the findings of Muir (1984), our evidence shows that planulae did not come from lipid bodies.

If planulae of Pocillopora damicornis in Okinawa are produced sexually, populations may, in part, be maintained by a combination of asexual reproduction via fragmentation and by local recruitment of genetically diverse larvae. One might also expect episodic longdistance dispersal. Populations of $P$. damicornis in the Ryukyu Islands are not completely dominated by a single or a few clones (Adjeroud \& Tsuchiya 1999), while populations from southwestern Australia are dominated by a few clones (Stoddart 1984a). However, the levels of gene flow between populations in the Ryukyu Islands were not so high as in the GBR (Benzie et al. 1995, Ayre et al. 1997). Adjeroud \& Tsuchiya (1999) suggested that the relative importance of asexual reproduction in $P$. damicornis varies geographically.

Large geographic variation in life history has been suggested for Pocillopora damicornis (e.g. Richmond 1987, Ayre et al. 1997). The Okinawan population of $P$. damicornis seems different from southwestern Australian populations studied by Stoddart \& Black (1985) and Ward (1992). While Ward (1992) found a large number of male colonies in addition to hermaphroditic colonies at Rottnest Island, we found only female and hermaphroditic colonies in Okinawa. The possibility that the populations in Okinawa and those in southwestern Australia belong to different species cannot be excluded. The possibility that $P$. damicornis might be a species complex or consist of distinct species has been suggested (Knowlton \& Jackson 1994, Ayre et al. 1997).

The present observation of early embryos about the size of mature oocytes, together with lack of any sign of production of planulae by budding, along with the disappearance of mature testes at about the time of initiation of embryogenesis, strongly suggest that planulae of Pocillopora damicornis in the Okinawan populations we studied are derived from oocytes and are probably produced sexually. However, genetic studies on the relationship between parent and offspring are necessary to determine whether the planulae in this population are derived from fertilized eggs or parthenogenetic development of oocytes.

Acknowledgements. This study was partly supported by Grants-in-Aid from the Ministry of Education, Science, Sports and Culture of Japan (Monbusho International Scientific Research Program: Joint Research). We thank staff of Sesoko Station, Tropical Biosphere Research Center, where part of this study was done.

\section{LITERATURE CITED}

Adjeroud M, Tsuchiya M (1999) Genetic variation and clonal structure in the scleractinian coral Pocillopora damicornis in the Ryukyu Archipelago, southern Japan. Mar Biol 134: $753-760$

Atoda K (1947) The larva and postlarval development of some reef-building corals. I. Pocillopora damicornis cespitosa (Dana). Sci Rep Tohoku Univ Ser 4, 18:24-47

Ayre DJ, Hughes TP, Standish RJ (1997) Genetic differentiation, reproductive mode, and gene flow in the brooding coral Pocillopora damicornis along the Great Barrier Reef, Australia. Mar Ecol Prog Ser 159:165-174

Benzie JHA, Haskel A, Lehman H (1995) Variation in the genetic composition of coral (Pocillopora damicornis and Acropora palifera) populations from different reef habitats. Mar Biol 121:731-739

Chornesky EA, Peters EC (1987) Sexual reproduction and colony growth in the scleractinian coral Porites astreoides. Biol Bull 172:161-177

Fadlallah YH, Pearse JS (1982) Sexual reproduction in solitary corals: overlapping oogenic and brooding cycles and benthic planulae in Balanophyllia elegans. Mar Biol 71: 223-231

Harrigan JF (1972) The planula larva of Pocillopora damicornis: Iunar periodicity of swarming and substratum selection behaviour. PhD thesis, University of Hawaii, Honolulu

Harriott VJ (1983) Reproductive seasonality, settlement, and post-settlement mortality of Pocillopora damicornis (Linnaeus) at Lizard Island, Great Barrier Reef. Coral Reefs 2: 151-157

Hidaka M (1985) Tissue compatibility between colonies and between newly settled larvae of Pocillopora damicornis. Coral Reefs 4:111-116

Knowlton N, Jackson JBC (1994) New taxonomy and niche partitioning on coral reefs: jack of all trades or master of some? Trends Ecol Evol 9:7-9

Kojis BL (1986) Sexual reproduction in Acropora (Isopora) species (Coelenterata: Scleractinia). I. A. cuneata and $A$. palifera on Heron Island Reef, Great Barrier Reef. Mar Biol 91:291-309

Martin-Chavez E (1986) Gametogenesis and origin of the planulae in the hermatypic coral Pocillopora damicornis. 
In: Jokiel PL, Richmond RH, Rogers RA (eds) Coral reef population biology. Hawaii Inst Mar Biol Tech Rep 37: 193-205

Muir P (1984) Periodicity and asexual planulae production in Pocillopora damicornis (Linnaeus) at Magnetic Island. Honour's thesis, James Cook University of North Queensland, Townsville.

Richmond RH (1987) Energetic relationships and biogeographical differences among fecundity, growth and reproduction in the reef coral Pocillopora damicornis. Bull Mar Sci 41:594-604

Richmond RH, Jokiel PL (1984) Lunar periodicity in larva release in the reef coral Pocillopora damicornis at Enewetak and Hawaii. Bull Mar Sci 34:280-287

Stimson JS (1978) Mode and timing of reproduction in some common hermatypic corals of Hawaii and Enewetak. Mar Biol 48:173-184

Stoddart JA (1983) Asexual production of planulae in the coral Pocillopora damicornis. Mar Biol 76:279-284

Stoddart JA (1984a) Genetical structure within populations of the coral Pocillopora damicornis. Mar Biol 81:19-30

Editorial responsibility: Otto Kinne (Editor),

Oldendorf/Luhe, Germany
Stoddart JA (1984b) Genetic differentiation amongst populations of the coral Pocillopora damicornis off Southwestern Australia. Coral Reefs 3:149-156

Stoddart JA, Black R (1985) Cycles of gametogenesis and planulation in the coral Pocillopora damicornis. Mar Ecol Prog Ser 23:153-164

Szmant-Froelich A, Reutter M, Riggs L (1985) Sexual reproduction of Favia fragum (Esper): lunar patterns of gametogenesis, embryogenesis and planulation in Puerto Rico. Bull Mar Sci 37:880-892

Tanner JE (1996) Seasonality and lunar periodicity in the reproduction of Pocilloporid corals. Coral Reefs 15:59-66

Tomascik T, Sander F (1987) Effects of eutrophication on reefbuilding corals. III. Reproduction of the reef-building coral Porites porites. Mar Biol 94:77-94

Ushioda T (1983) Reproductive cycle of Pocillopora damicornis. Graduation thesis, University of the Ryukyus, Okinawa (in Japanese)

Ward S (1992) Evidence for broadcast spawning as well as brooding in the scleractinian coral Pocillopora damicornis. Mar Biol 112:641-646

Submitted: July 14, 1999; Accepted: December 21, 1999 Proofs received from author(s): June 26, 2000 